\title{
Devascularization Surgical Model of Acute Liver Failure in Minipigs
}

\author{
M. Ryska ${ }^{a}$ E. Kieslichováb T. Pantoflíček ${ }^{a}$ O. Ryska ${ }^{a}$ R. Zazulab \\ J. Skibováa M. Hájekc \\ aTransplant Surgery Department, Departments of ${ }^{\mathrm{b}}$ Anesthesiology, Resuscitation and Intensive Care, \\ cRadiodiagnostic and Interventional Radiology, Institute for Clinical and Experimental Medicine, \\ Prague, Czech Republic
}

\section{Key Words \\ Acute liver failure · Surgical pig model $\cdot$ Intracranial pressure $\cdot$ Hypoglycemia. Therapeutic window}

\begin{abstract}
Aim: The study was designed to develop a readily reproducible model of acute liver failure (ALF) in the minipig, to gain an 8-hour therapeutic window to mimic, as closely as possible, acute liver failure in man. Method: We used reversible devascularization model of ALF in the minipig involving hepatic artery ligation and establish an end-to-side portocaval anastomosis. Standard laboratory monitoring was complemented with intracranial pressure (ICP) measurement. Material: Twenty minipigs (weight $25-30 \mathrm{~kg}$ ) were used for the experiment. The animals were divided into 3 groups: I: 10 animals in an experimental group with ALF; II: 5 animals in an experimental group with ALF and ICP measurement, and III: 5 animals in a control group without ALF. Results: Laboratory testing has shown the significant changes in levels of AST (33.44 \pm 39.96 vs. $1.56 \pm 0.50 \mathrm{mmol} / \mathrm{l})$, lactate $(2.97 \pm 1.16$ vs. $1.18 \pm 0.61 \mathrm{mmol} / \mathrm{l})$, and ammonia (264.3 \pm 93.05 vs. $42.5 \pm 12.98 \mathrm{mmol} / \mathrm{l})$ between ALF
\end{abstract}

\begin{tabular}{ll}
\hline KARGER & (c) 2004 S. Karger AG, Basel \\
0014-312X/04/0363-0179\$21.00/0 \\
Fax +4161306 1234 \\
$\begin{array}{l}\text { E-Mail karger@karger.ch } \\
\text { www.karger.com }\end{array}$ & $\begin{array}{l}\text { Accessible online at: } \\
\text { www.karger.com/esr }\end{array}$
\end{tabular}

groups and controls $(p<001) 6 \mathrm{~h}$ after the operative procedure, and significant changes in hypoglycemia and intracranial pressure were found $4 \mathrm{~h}$ after the operative procedure. The difference in Quick values (67.4 \pm 17.03 vs. $75.2 \pm 2.68$ ) was not significant. We assume that the therapeutic window starts $4 \mathrm{~h}$ after the beginning of the experiment. Conclusion: Our devascularization model of ALF is simple and readily reproducible. The therapeutic window occurring shortly after surgery and persisting for a mean $9 \mathrm{~h}$ is suitable to evaluate bioartificial liver devices.

Copyright $\odot 2004$ S. Karger AG, Basel

\section{Introduction}

Acute liver failure (ALF) is a clinical syndrome involving massive hepatocyte necrosis, and resulting in failure of liver function and in the development of encephalopathy. Despite tremendous advances in intensive care, survival of patients with ALF, depending on progression of encephalopathy and development of fatal infectious complications, reaches more than $40 \%$ when managed by conservative therapy [1]. The introduction of liver transplan-

Prof. Miroslav Ryska, MD, PhD

Transplant Surgery Department

Institute for Clinical and Experimental Medicine, Vídeňská 1958/9

CZ-140 21 Prague (Czech Republic)

Tel. +420261364105, Fax +420261362822, E-Mail miry@medicon.cz 
tation into clinical practice improved patients' chances of survival. However, a number of questions related to ALF management have not been satisfactory resolved; hence many studies concerned with the development of biological elimination methods employing animal or human isolated hepatocytes in recent years were performed [2-4]. To test the efficacy of these methods, a model which would mimic ALF, as closely as possible, in man on a large laboratory animal is necessary. At the same time, the model should feature an adequately long therapeutic window allowing the subsequent evaluation of bioartificial liver devices, which can be potentially introduced in the treatment of ALF in man. The following criteria of an ideal model of ALF have been generally accepted [5]: (1) the liver failure should be potentially reversible; (2) the model must be reproducible; (3) liver injury should result in the death of the animal as it is in clinical practice whereby ALF leads to death of the patient; (4) an adequately big therapeutic window must be created, and (5) any toxins must pose minimal risk to staff (applicable to a chemical model).

Essentially, there were two approaches to developing a surgical model of ALF: an anhepatic, and a devascularization approach.

The first to develop a surgical model were Minkowski and Nauny [6] in 1886. This experiment provided the basis for an anhepatic model of ALF in a laboratory animal. The basic premise/prerequisite is to maintain flow in the vena cava inferior bed connected to the portal vein using a three-way catheter [7]. The absence of necrotic hepatic tissue in the body means that development of ALF has no correlate in human medicine: there is no rise in the serum levels of aromatic amino acids (methionine, tyrosine, phenylalanine, and tryptophan) [8]. Other disadvantages of the model are the blood loss secondary to hepatectomy and the frequent need for blood transfusion affecting the degree of ALF [9]. Moreover, the survival of experimental animals does not differ from those seen in the devascularization model [9].

A devascularization model was first described by Rappaport in 1953 [9-13]. It is usually created by establishing a portocaval anastomosis (PCA) with subsequent hepatic artery ligation (HAL) [14]. This basic procedure is modified by the technique of HAL. ALF's irreversibility can be avoided by compression of the hepatic artery for only a short period of time [10]. No blood loss occurs in the event of liver devascularization and PCA. The presence of necrotic hepatic tissue results in a course of ALF comparable to that of man.
The aim of our study was to develop a readily reproducible model of ALF in the minipig, and to measure intracranial pressure (ICP) before and during the therapeutic window, which should be $8 \mathrm{~h}$.

\section{Experimental Procedures}

\section{Animals}

Twenty adult laboratory pigs from total number of 27 (minipigs from veterinary laboratory of Czech Academy of Science) with a weight of $25-30 \mathrm{~kg}$ were used in the experiment. Fifteen of them were used to develop the model ALF in experimental group I and II (with ICP measurement). Group III, which included 5 animals, was established as a control group and was provided with the same preoperative preparation and laparotomy as the experimental groups I and II.

All experiments were carried out in accordance with the European Communities Council Directive of 24 November 1986 (86/609/ EEC).

\section{Surgical Procedure}

\section{ALF Model Surgery}

Laparotomy was performed in midline from the processus xiphoideus down to the lower abdomen. After mobilization of the portal vein and IVC, a portocaval shunt was established end-to-side. This was followed by ligation of the common hepatic artery or its branches.

Epicystostomy and choledochostomy were established for postoperative monitoring. The surgical procedure was completed by introducing a drain into the abdominal cavity and by the insertion of a gastrostomy to drain gastric content. The operative wound was closed in a single layer, the minipig was laid on its side, left on the operating table with intubations and kept warm. The preparation of animals for ICP study was the same as above, only on closing the laparotomy, a temporoparietal sensor was inserted intracranially for continuous intracranial pressure (ICP) monitoring. This surgical modification does not require any transfusion during the whole experiment.

\section{Control Surgery}

Laboratory animals of controls groups underwent identical preparation including the creation of vascular access; following laparotomy, epicystostomy and gastrostomy, wounds were closed with drain.

\section{Animal Care}

Prior to surgery, animals were kept fasting for $12 \mathrm{~h}$, with water available ad libitum. Prior to surgery, the animals were pretreated with a combination of ketamine $5 \mathrm{mg} / \mathrm{kg}$ body weight (Ketaset, Fort Dodge, USA), atropine $0.1 \mathrm{mg} / \mathrm{kg}$ (Atropin; Hoechst-Biotika, Germany), and azaperone $5 \mathrm{mg} / \mathrm{kg}$ (Stressnil, Jansen, Belgium) intramuscularly. Once laid on the operating table, the ear vein was cannulated and general anesthesia was induced with ketamine $5 \mathrm{mg} / \mathrm{kg}$ (Narkamon; Spofa, Czech Republic) and metomidate $2-5 \mathrm{mg} / \mathrm{kg}$ (Hypnodil; Janssen, Belgium). Following endotracheal intubation, animals were 
relaxed using pipecuronium at a dose of $50 \mu \mathrm{g} / \mathrm{kg}$ (Arduan; Chemical Works of Gedeon Richter, Hungary) and as needed thereafter, while receiving mechanical ventilation with a mixture of oxygen and nitric oxide. Anesthesia was complemented with repeat doses of fentanyl $100 \mu \mathrm{g}$ (Fentanyl; Janssen) and etomidate 10-20 mg i.v. (Hypnomidate; Janssen) at 30-min intervals. Heparin 500 IU (Heparin, Léčiva, Czech Republic) was administered to prevent thromboembolism, and famotidine (Quamatel; Chemical Works, Hungary) was administered intravenously to prevent stress-related mucosal injury. Antibiotic based prophylaxis was provided with amoxicillin $1.2 \mathrm{~g}$ intravenously (Augmentin, Léčiva, Czech Republic). After general anesthesia induction, an 18-G catheter (Braun, Germany) was inserted into the femoral artery for direct blood pressure measurement. A double lumen catheter ( $7 \mathrm{Fr}$; Arrow, USA) was inserted into the femoral vein for drug and infusion delivery. A flow directed thermodilution catheter (7 Fr; Arrow) was inserted into the pulmonary artery via the right internal jugular vein to measure hemodynamic parameters. The parameters monitored intraoperatively included EKG, blood pressure, CVP, PAP, PCWP, CO, CI, SVRI, $\mathrm{SpO}_{2}, \mathrm{ETCO}_{2}$, central and peripheral body temperature (multichannel recorder; Marguette, USA) and hourly diuresis. At the start of the procedure and after clamp release, arterial blood was collected to determine biochemical parameters, blood count and coagulation time, ABB, iontogram, lactate, and glycemia. Crystalloid solutions were infused at a rate of 20 $50 \mathrm{ml} / \mathrm{h}$, and/or colloids as needed.

\section{Postoperative Care and Monitoring}

After the procedure, the animal was laid on its side, was warmed and received mechanical ventilation with a mixture of oxygen and air, with $\mathrm{FiO}_{2}$ of 0.5 .

Intravenous analgosedation was delivered constantly using drugs with a predominantly extrahepatic route of elimination. We used a combination of propofol at a starting dose of $6 \mathrm{mg} / \mathrm{kg} / \mathrm{h}$ (Recofol; Leiras, Finland), remifentanil at a starting dose of $1 \mu \mathrm{g} / \mathrm{kg} / \mathrm{min}$ (Ultiva; Glaxo Group, UK), and medetomidine at a starting dose of $3 \mu \mathrm{g} / \mathrm{kg} / \mathrm{h}$ (Domitor; Pfizer, USA). In the presence of hypoglycemia under $3.5 \mathrm{mmol} / 1$ during the onset of liver failure, $40 \%$ glucose was administered in continuous infusion at a dose of $1 \mathrm{ml}$ per $\mathrm{kg}$ body weight of the animal. Crystalloids and colloids were administered depending on status, and/or ionic agents were administered to maintain perfusion pressure and diuretics. Hemodynamic parameters, internal milieu, hepatic and renal function as well as body temperature were monitored.

To maintain satisfactory blood pressure levels, noradrenaline (Noradrenalin, Léčiva, Czech Republic) and/or furosemide (Furosemid; Hoechst-Biotica, Slovakia) in bolus form were administered as necessary to enhance diuresis. The monitored parameters included hemodynamic parameters, $\mathrm{SpO}_{2}, \mathrm{ETCO}_{2}$, body temperature, and hourly diuresis. Blood samples were collected at regular intervals to determine parameters of internal environment, acid-base balance, ion values, blood count, blood coagulation; liver tests were performed and serum creatinine determined.

Intracranial pressure (ICP) measurement was initiated immediately after surgery by introducing ICP sensor (microsensor basic kit for subdural, intraparenchymal procedure; Codman, Johnson \& Johnson, USA). Once the monitor was in place, the ICP was continuously monitored.

The experiment was stopped after a successful 8-hour therapeutic window (approx. $12 \mathrm{~h}$ after the start of the operation) by administering $20 \mathrm{ml}$ of $5 \% \mathrm{KCl}$ solution. This was followed by relaparotomy, revision of the abdominal cavity, and specimens of the liver and spleen were taken for histology examination.

Data were processed statistically using the t test and the MannWhitney nonparametric test by using EXCEL and QUATRO statistical procedures.

\section{Results and Discussion}

To carry out our experiment, we followed the devascularization model by establishing a portocaval anastomosis (PCA) with subsequent hepatic artery ligation (HAL) [14]. We consider it crucial not to give blood transfusions. Ten minipigs from group I had a mean survival time of $13 \mathrm{~h}$ (range 11.7-15.2 h) which was similar to the survival time of animals in the control group. We fixed the overall duration of the experiment to maintain an experimental therapeutic window in the range of $8 \mathrm{~h}$, which is sufficient for the planned experiments. Table 1 summarizes the mean values of AST, lactate, Quick, and ammonia in either group with standard deviation (SD). A comparison of the mean measured values in individual laboratory parameters at 3-hour intervals and the statistical significance of differences in mean values, obtained using the MannWhitney nonparametric test, show that significant differences in ALF development start between 3 and $6 \mathrm{~h}$ after the procedure and are characterized by changes in AST, and increased lactate and ammonia concentration which are typical ischemic changes. We tested glycemia in 30min interval, and its decrease below $3.9 \mathrm{mmol} / \mathrm{l}$ was considered as the beginning of therapeutic window (mean $\sim 4 \mathrm{~h}$, range $2.5-6.5 \mathrm{~h}$ ). Individual survival times and the start of hypoglycemia are summarized in figure 1.

In 5 animals (group 2) with induced ALF, we studied changes of intracranial pressure during the therapeutic window. Characteristic laboratory values of this group are summarized in table 1 and they are the same as in group 1.

Table 2 and figure 2 show the development of intracranial pressure. The increase in pressure is linear and a significant change of ICP, compared to the normal value, was found after $3 \mathrm{~h}$. Compared with laboratory data where hypoglycemia was established 4-6 h from ICP measurement, we can specify the mean start time of ALF to $4 \mathrm{~h}$ after the operation procedure. There is good correlation between the significant change of the concentration of glucose and ICP. In the control group, no instances of a marked decrease in glycemia were seen in the postoperative period. 
Table 1. Mean values and standard deviations (SD) of individual laboratory markers of ALF of groups I (ALF) and III (controls)

\begin{tabular}{lllllll}
\hline & $0 \mathrm{~h}$ & $3 \mathrm{~h}$ & $6 \mathrm{~h}$ & $9 \mathrm{~h}$ & $12 \mathrm{~h}$ & $15 \mathrm{~h}$ \\
\hline AST, $\mu$ kat/l & n.s. & n.s. & $\mathrm{p}<0.01$ & $\mathrm{p}<0.01$ & $\mathrm{p}<0.01$ \\
I & $0.83 \pm 0.29$ & $14.37 \pm 35.55$ & $33.44 \pm 39.96$ & $40.88 \pm 41.34$ & $54.94 \pm 43.22$ \\
III & $0.82 \pm 0.30$ & $1.08 \pm 0.25$ & $1.56 \pm 0.50$ & $1.68 \pm 0.75$ & $1.36 \pm 0.65$ & $1.32 \pm 0.45$ \\
Lactate, mmol/1 & n.s. & n.s. & $\mathrm{p}<0.01$ & $\mathrm{p}<0.01$ & $\mathrm{p}<0.01$ & - \\
I & $3.97 \pm 1.62$ & $4.52 \pm 1.87$ & $2.97 \pm 1.16$ & $2.75 \pm 1.08$ & $3.49 \pm 1.64$ & $0.76 \pm 0.32$ \\
III & $4.08 \pm 1.34$ & $3.20 \pm 1.74$ & $1.18 \pm 0.61$ & $0.86 \pm 0.29$ & $0.75 \pm 0.21$ \\
Quick, \% & n.s. & n.s. & n.s. & n.s. & n.s. \\
I & $82.4 \pm 11.41$ & $83.3 \pm 13.06$ & $67.4 \pm 17.03$ & $56.0 \pm 27.48$ & $51.6 \pm 21.52$ & - \\
III & $85.6 \pm 5.13$ & $74.2 \pm 3.56$ & $75.2 \pm 2.68$ & $74.2 \pm 2.17$ & $73.8 \pm 6.10$ & $68.0 \pm 1.00$ \\
Ammonia, mmol/1 & n.s. & - & $\mathrm{p}<0.01$ & $\mathrm{p}<0.01$ & $\mathrm{p}<0.01$ & - \\
I & $44.8 \pm 19.25$ & $173.8 \pm 61.22$ & $264.3 \pm 93.05$ & $350.7 \pm 159.49$ & $463.4 \pm 178.47$ & \\
III & $29.7 \pm 9.74$ & $34.4 \pm 5.66$ & $42.5 \pm 12.98$ & $61.4 \pm 31.39$ & $41.0 \pm 11.02$ & $37.2 \pm 5.24$ \\
\hline
\end{tabular}

n.s. $=$ Not significant $; \mathrm{p}<0.01=$ statistically significant differences of mean values.

Fig 1. Survival time of laboratory animals with onset of hypoglycemia shown. Dotted line represents mean value of the therapeutic window (hypoglycemia $<3.9 \mathrm{mmol} / \mathrm{l}$ ).

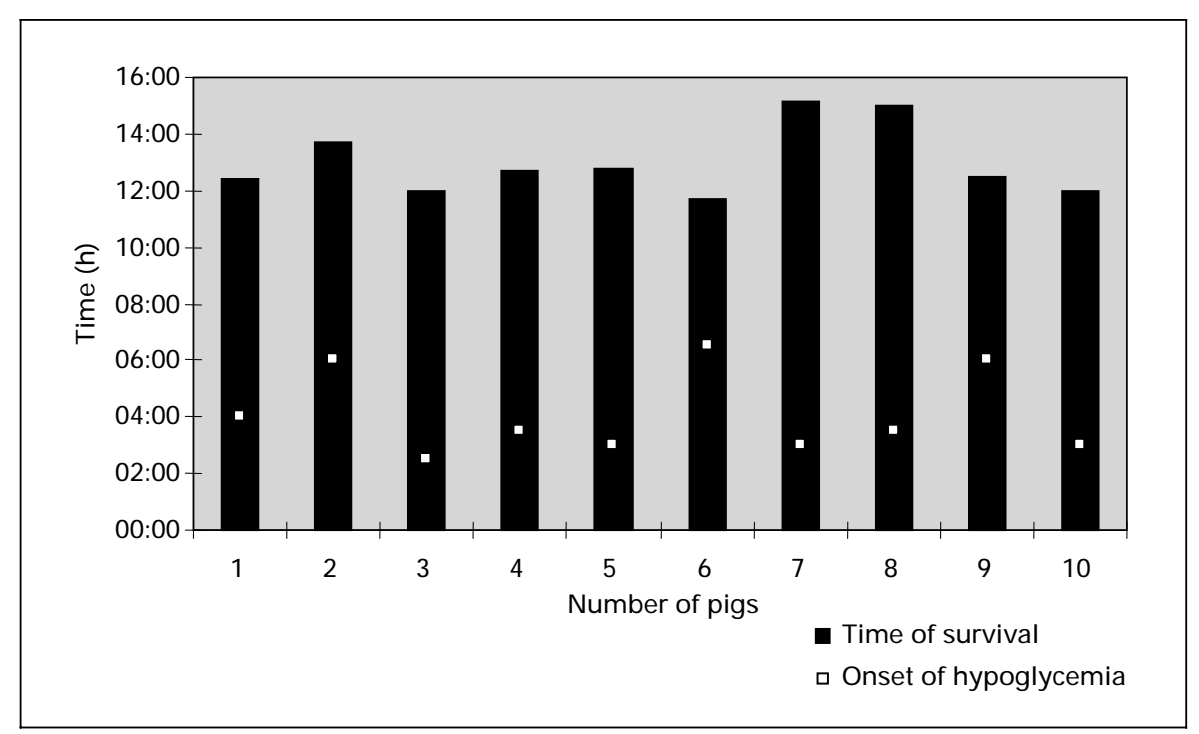

Hypothermia influences the value of ICP and moderate hypothermia is useful in the treatment of the increase of ICP [15]. We have measured body temperature continuously and did not notify hypothermia because of active temperature regulation.

The significant difference in blood levels of lactate, given in table 1, is rather due to a decrease in lactate levels in control animals than due to an increase in the animals suffering from acute liver failure. The starting high levels of lactate were similar in both groups (vs. stress factor before operation). Lactate level was decreased after laparotomy in the control group with normal liver function. On the contrary, the starting lactate level in minipigs did not have that trend because of ALF. The certain role plays accelerated glycolysis in the splanchnic area [16].

Ammonia is not an indicator of liver ischemia but of splanchnic shunting of the portal blood passing the liver. Nevertheless, ammonia levels were monitored to have valid data for BAL treatment group of ALF in the future.

Our experiments confirmed that the devascularization is simple and easy to reproduce and results are easily comparable with previous studies on minipigs. De Groot et al. [10] reported a group of 15 pigs with PCA and temporary hepatic artery compression. Among the 13 animals which died within an interval of 15-20 h, ALF was the cause of death in only 8 of them. In an effort to conform to all the 
Table 2. Values of individual and mean values of intracranial pressure (ICP in $\mathrm{mm} \mathrm{Hg}$ ) of minipigs in group II (with ALF) measured after surgery

\begin{tabular}{lclllllllll}
\hline Experiment & \multicolumn{2}{l}{ Time after surgery } \\
\cline { 2 - 9 } & $1 \mathrm{~h}$ & $2 \mathrm{~h}$ & $3 \mathrm{~h}$ & $4 \mathrm{~h}$ & $5 \mathrm{~h}$ & $6 \mathrm{~h}$ & $7 \mathrm{~h}$ & $8 \mathrm{~h}$ & $9 \mathrm{~h}$ & $10 \mathrm{~h}$ \\
\hline 1 & 10 & 12 & 12 & 15 & 19 & 22 & 24 & 24 & 28 & 26 \\
2 & 9 & 16 & 10 & 15 & 17 & 17 & 20 & 23 & 24 & 38 \\
3 & 12 & 13 & 13 & 17 & 21 & 23 & 24 & 24 & 23 & 22 \\
4 & 12 & 15 & 13 & 19 & 21 & 22 & 26 & 28 & 27 & 28 \\
5 & 8 & 8 & 12 & 14 & 17 & 27 & 29 & 28 & 32 \\
Mean $\pm \mathrm{SD}$ & $10.2 \pm 1.8$ & $12.8 \pm 3.1$ & $12 \pm 1.2^{*}$ & $16 \pm 2.0^{*}$ & $19 \pm 2.0^{*}$ & $22.2 \pm 3.5^{*}$ & $24.6 \pm 3.3^{*}$ & $25.4 \pm 2.4^{*}$ & $26.8 \pm 3.5^{*}$ & $29.8 \pm 6.6^{*}$
\end{tabular}

* Significant difference from time 0 .

Fig. 2. Time course of ICP in the period of $10 \mathrm{~h}$, the linear dependence of the mean value of ICP is characterized by $r>0.98$.

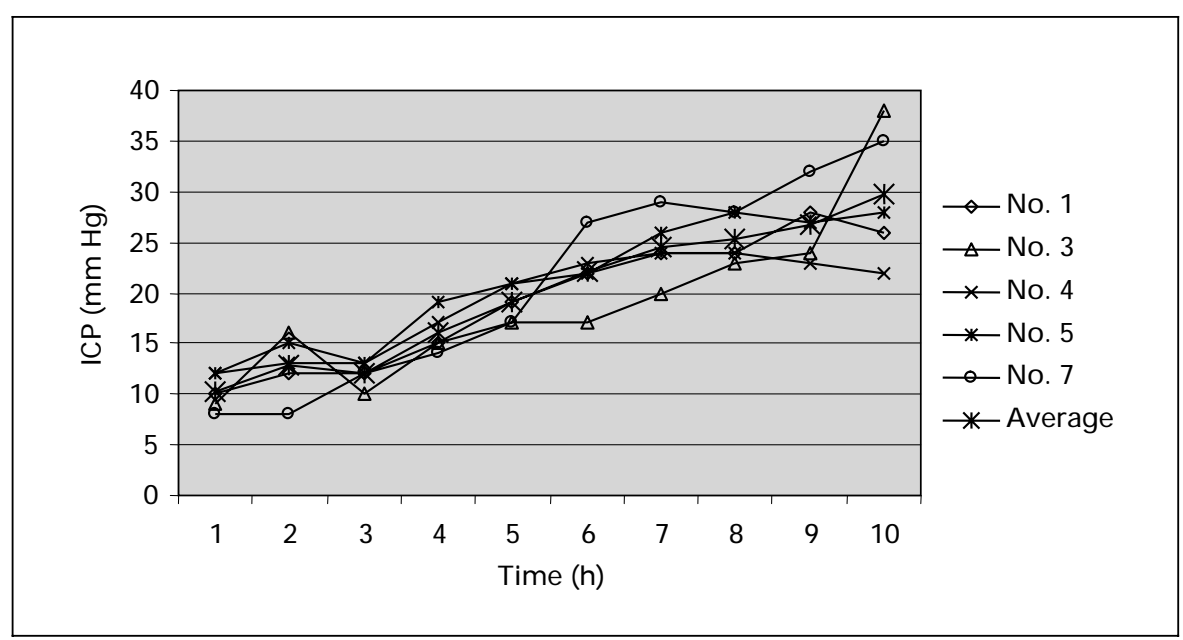

above criteria, Benois et al. [11] described a modified surgical model of ALF with temporary hepatic artery closure in 17 animals. The model was successful in 13 animals with an 8-hour therapeutic window. A total of 10 animals died due to hepatic coma.

Using our model, the minipigs entered falling off hypoglycemia $4 \mathrm{~h}$ after the operation. This time corresponded to a significant increasing of ICP. This condition was considered the onset of ALF and agrees with the other laboratory data manifesting the start of ALF between 3 and $6 \mathrm{~h}$ after the procedure.

Hypoglycemia results from defective gluconeogenesis in the falling liver as well as inadequate hepatic uptake of insulin leading to high peripheral insulin levels [17]. Therefore glycaemia level was measured as an important marker of the ALF development.

So the simple measurement of hypoglycemia and ICP can be used to determine the start of ALF.

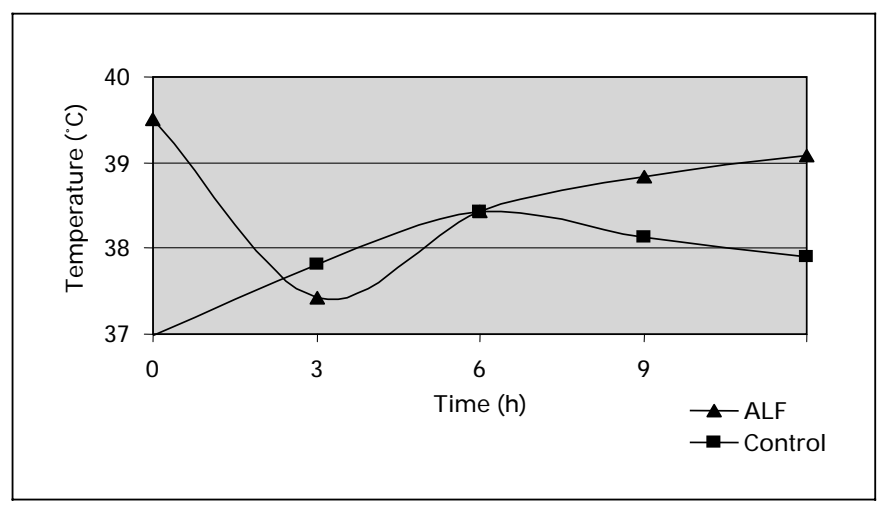

Fig. 3. Average temperature in minipigs with ALF and in the control group (difference is not significant starting $3 \mathrm{~h}$ after operation). 
We demonstrated a significant difference between the group with induced liver failure and the control group. This clinically relevant model allows the evaluation of new biotechnology, which may find use in the management of ALF in man.

\section{Acknowledgments}

The study was conducted in Research Centre LN00A065 and was funded by grant of Czech Ministry of Health CEZ: L17/ 98:00023001. The authors would like to thank Mr. J. Č́p, Mrs. M. Č́žková and Mr. M. Hmirák for technical assistance during the experiments.

\section{References}

1 Lee WM: Acute liver failure. $\mathrm{N}$ Eng $\mathrm{J}$ Med 1993;329:1862-1872.

2 Kamohara Y, Rozga J, Demetriou AA: Artificial liver: Review and Cedars Sinai experience. J Hepatobiliary Pancreat Surg 1998;5:273285.

3 Rozga J, Podesta L, Le Page E: A bioartificial liver to treat severe acute liver failure. Ann Surg 1994;219:538-543.

4 Gerlach J, Trost T, Ryan CJ, et al: Hybrid liver support system in a short-term application on hepatectomized pigs. Int J Artif Organs 1994; 17:549-553.

5 Terblanche J, Hickman R, Miller D: Animal Experience with Support Systems: Are These Appropriate Animal Models of Fulminant Hepatic Necrosis? Artificial Liver Support. London, Pitman, 1975, pp 163-172.

6 Minkowski O, Nauny B: Über den Icterus durch Polycholie und die Vorgänge in der Leber bei demselben. Arch Exp Path Pharmakol 1886;21:1-33.
7 Sosef MN, Abrahamse LSL, van de Kerkhove MP, et al: Assessment of the AMC bioartificial liver in the anhepatic pig. Transplantation 2002;73:204-209.

8 Newsome PN, Plevris JN, Nelson LJ, et al: Animal models of fulminant hepatic failure: A critical evaluation. Liver Transplant 2000;1: $21-31$

9 Tonnesen K: Experimental liver failure: A comparison between hepatectomy and hepatic devascularization in the pig. Acta Chir Scand 1997; 143:271-277.

10 de Groot GH, Reuvers CB, Schalm SW, et al: A reproducible model of acute hepatic failure by transient ischemia in the pig. J Surg Res 1987; 42:92-100.

11 Benois S, Sarkis R, Baudrimont M, et al: A reversible model of acute hepatic failure by temporary hepatic ischemia in the pig. J Surg Res 2000;88:63-69.
12 Janke J, Gerlach J, Kardassis D, Böhmer C, Rossaint R: Effect of a hybrid liver support system on cardiopulmonary function in healthy pigs. Int J Artificial Organs 1997;20:570-575.

13 Rappaport AM, McDonald MH, Borowny ZL Hepatic coma following ischemia of the liver. SGO 1953;97:748-755.

14 Hanid MA, Mackenzie RL, Jenne RE, et al: Intracranial pressure in pigs with surgically induced acute liver failure. Gastroenterology 1979;76:123-131.

15 Jalan R, Damink SWMO, Deutz NEP, et al: Moderate hypothermia for uncontrolled intracranial hypertension in acute liver failure. Lancet 1999;354:1164-1168.

16 Clemmesen JO, Hoy CE, Kondrup J, et al: Splanchnic metabolism of fuel substrates in acute liver failure. J Hepatol 2000;33:941948.

17 Lee WM: Acute liver failure. NEJM 1993;329: 1862-1869. 